\title{
LA PARTÍCULA Y TAL EN EL ESPAÑOL HABLADO DE VALENCIA
}

\author{
Marta Pilar Montañez Mesas \\ (Universitat de València. Grupo Val.Es.Co.) \\ Marta.Montanez@uv.es
}

\begin{abstract}
Resumen
Este trabajo estudia las funciones pragmáticas y la variación de la partícula y tal en el español hablado de Valencia y en Valencia. Para analizar esta variación tomamos como variantes las formas $/ y$ tall $\sim 10$ tall $\sim$ tall y describimos en qué contextos se neutralizan sus diferencias funcionales, semánticas o pragmáticas. Especialmente, prestamos atención a la posición final en unidades de habla, esto es, a su posición discursiva. Para ello comparamos su uso tanto en entrevistas semidirigidas, como en conversaciones coloquiales. En este trabajo con corpus, integramos no solo los factores lingüísticos que determinan los usos de las partículas discursivas, sino también ciertos valores sociolingüísticos, como el sexo, edad, nivel sociocultural, tipo de secuencias lingüísticas, género discursivo, entre otros.

PALABRAS CLAVE: partículas discursivas, pragmática, posición discursiva, lingüistica con corpus.
\end{abstract}

\begin{abstract}
This paper studies the pragmatic functions and the variation of the particle $y \mathrm{tal}$ in the Spoken Spanish language of Valencia and in Valencia. To analyse the variation, we accept as variants $/ y$ tall $\sim$ lo tall $~$ Ital' forms and we describe in what contexts they neutralized their functional, semantic and pragmatic differences. Specially, we pay attention in their final position in the units of talk, that is, the discursive position. We compare its use in both informal reviews and colloquial conversations. In this corpus-based work we integrate not only the linguistic factors that determinate the uses of the discourse particles, but also the sociolinguistic items, like sex, age, social level, type of linguistic sequences, genre, and others.
\end{abstract}

KEYWORDS: discourse particles, Pragmatics, discursive position, corpus-based paper.

\section{Introducción. Presentación y objetivos}

El presente trabajo pretende colaborar en el estudio del español hablado de Valencia'. Se trata del análisis descriptivo y explicativo de la partícula /y tal/ y su posible variación intraidiomática ${ }^{2}$, puesto que detectamos las formas /tal/ y $/ \mathrm{o} \mathrm{tal} / \mathrm{en}$ las mismas posiciones discursivas. El reciente aumento de su uso hace necesario un examen pormenorizado de su funcionamiento lingüístico y, para ello, hemos partido del corpus Val.Es.Co. de entrevistas El español hablado de Valencia, que forma parte del PRESEEA (Proyecto para el estudio sociolingüistico del español de España y América). En concreto, nos hemos centrado en el corpus referido al nivel sociocultural alto y medio ${ }^{3}$, como detallaremos más adelante. La

1 Este trabajo se enmarca dentro del proyecto de investigación "Nuevas aportaciones al Diccionario de particulas discursivas del español (DPDE)", subvencionado por el Ministerio de Educación y Ciencia (HUM2004-01453/ FILO), así como por fondos FEDER. Agradezco los valiosos comentarios de D. Antonio Briz y D. José Ramón Gómez.

2 No empleamos 'variación' stricto sensu, sino en sentido amplio, como alternancia de estas formas en los mismos contextos de uso y con el mismo valor pragmático.

3 Aunque el nivel bajo ya ha sido publicado (Gómez Molina, cood., 2007) aún permanecía inédito en el momento en que iniciamos la investigación que contiene este artículo. 
comunidad de habla objeto de nuestro estudio es el área metropolitana de Valencia, cuya realidad bilingüe se presta a un mayor interés lingüístico. Dado que uno de los factores lingüísticos que tenemos en cuenta es el género discursivo y el registro, comparamos estos valores con otro corpus de lengua hablada, pero de conversaciones coloquiales (Briz y grupo Val.Es.Co., 2002), aunque solo aquellas conversaciones de la segunda parte, que se ordenan según el nivel sociocultural de los informantes, de las que tomamos, igualmente, aquellas referidas al nivel medio y alto, para que la comparación entre ambos corpus de referencia sea coherente y los resultados, científicos.

A la hora de analizar las ocurrencias del corpus, aunque no realizamos un estudio sociolingüístico en sentido estricto, tendremos en cuenta diversos factores sociológicos que $a$ priori nos parecen relevantes para este estudio: sexo, edad y lengua materna del informante, así como factores lingüísticos: el cotexto, el registro y el tipo de secuencia en la que aparece la partícula. Todos estos factores aparecen como campos en la ficha técnica que empleamos para anotar las características de cada ocurrencia.

Como hipótesis de partida, y una vez observada la comunidad de habla que nos ocupa, consideramos que se produce neutralización en el discurso de las formas $[\mathrm{tal}] \sim[0 \mathrm{tal}] \sim$ $[y \mathrm{tal}]$ en una determinada posición, esto es, en posición final de la unidad a la que afectan cuando les sigue una pausa. Esta marca fónica es fácilmente reconocible en el análisis del corpus, puesto que se recoge en la transcripción con una o varias barras oblicuas, según la durración de la pausa (/). Si se comprueba que se produce tal neutralización, estaríamos ante un fenómeno de variación sintáctica. Antes de profundizar en la comparación de estas formas, para poder valorar si existe o no dicha variación, será preciso, apuntar una breve descripción teórica sobre esta partícula, así como establecer los valores discursivos que nos permiten afirmar que existe neutralización.

\section{Marco de referencia}

\subsection{Breve apunte teórico}

La partícula $/ y \mathrm{tal} /$ comparte valores con /tal/ y lo tall, cuando aparece en posición final de la unidad a la que se refiere y va seguido de pausa, como hemos explicado, por lo que estas formas pueden neutralizarse en el discurso. Si son equifuncionales es quizá porque tal posee una función o valor primario que se mantiene en todas ellas y que se explica por su propia categoría gramatical. Según la gramática tradicional, tal es un pronombre indefinido, es decir, actúa como sustituto de otros nombres. Tras esta valoración preliminar, detengámonos un poco más en su valor.

En la descripción de esta partícula podemos seguir el esquema clásico forma, función y significado, pero será un análisis incompleto si no la valoramos desde otras perspectivas de la lengua. Como punto de partida, acudimos a diversos diccionarios en los que aparece descrita. En primer lugar, hay diccionarios que no la incluyen, como el Diccionario de uso del español, de María Moliner. La ausencia de esta forma en un diccionario descriptivo como éste puede indicarnos que su frecuencia de uso es relativamente reciente, ya que el diccionario no lo es tanto. Otra gran obra lexicográfica descriptiva, el diccionario Lema, sí la recoge e indica en la microestructura que se trata de una forma "coloquial", que sirve "para omitir detalles poco relevantes del relato", y define de modo similar la combinación 
tal y cual. También el Diccionario del español actual, de Manuel Seco, indica ese carácter coloquial y la describe como "fórmula con que se concluye vagamente una frase"; pero Seco no indica que sea un dato poco importante, simplemente destaca su valor conclusivo. Por su parte, el $D R A E$ considera que $/ y$ tal/ es una "expresión" adecuada para "añadir un término poco preciso, pero semejante a lo ya dicho".

De estas descripciones destacamos la de M. Seco, pues resalta la función conclusiva de y tall, y el matiz aportado por el $L E M A$, sobre el tipo de discurso en el que aparece con mayor frecuencia, el relato. Podemos adelantar que, en nuestro corpus, un alto porcentaje de ocurrencias funcionan como cierre de una enumeración o de una secuencia narrativa. Hay que diferenciar entre dos tipos de discurso narrativo presentes en las entrevistas y en las conversaciones analizadas:

a) secuencia narrativa (con planificación simultánea), y

b) relato conversacional (recuerdo, discurso repetido)

Por un lado, la secuencia narrativa es aquella en la que, de forma simultánea, el hablante narra un hecho o anécdota y lo planifica sobre la marcha como respuesta a la intervención de su interlocutor; y por otro lado, el llamado por Bronckart y otros (1985, apud., Gómez Molina, 2005: 35) relato conversacional, que también se recoge en las transcripciones del corpus de conversaciones del grupo Val.Es.Co (2002), y que consiste en la recuperación de un discurso previo, que no se produce sobre la marcha, sino que se recuerda, y se reproduce en estilo directo lo dicho (o leído) en otra ocasión e incluso por otra persona ${ }^{4}$, en una situación comunicativa anterior. Es fácil de reconocer puesto que se marca tipográficamente con la letra cursiva en la transcripción.

En nuestro corpus aparecen numerosas ocurrencias en esos relatos conversacionales, hecho que puede deberse a que el hablante recupera una información anterior; la repetición (o recuerdo) no es exacta, y ha de suplir parte de la información con elementos sustitutos, de ahí que pensemos que mantiene parte de su carácter o significado pronominal.

\subsubsection{Forma}

En cuanto a su forma, la partícula /y tal/ está formada por la conjunción copulativa " $y$ " y el pronombre indefinido $t_{a l} l^{5}$. Debido a la neutralización que se produce en el discurso con otras formas similares, nos planteamos si pervive el valor de tal o bien la forma $/ y$ tal/ se ha fijado como partícula y ha adquirido un significado propio. También nos cuestionamos si posee por sí misma el valor conclusivo, o éste lo adquiere en el discurso por aparecer situada en posición final o bien, el valor de cierre lo da la propia conjunción copulativa.

Las respuestas a estas cuestiones las hallamos en la variación que ofrece el corpus. Si en las ocurrencias analizadas las formas tal / y tal / o tal son equifuncionales desde el punto de vista discursivo, significa que se mantiene un valor común en todas ellas y por tanto,

4 En muchos ejemplos el informante adapta la voz al mensaje: cambia el tono, la intensidad (susurra), e incluso, imita la voz del hablante que emitió originariamente ese fragmento de discurso.

5 No se consideran objeto de nuestro estudio los usos puramente indefinidos de 'tal' del tipo: acciones de tal empresa (p. 305), le entró tal pánico (p. 370), donde posee un valor cercano al demostrativo. Ambos ejemplos han sido extraídos del corpus de entrevistas perteneciente al nivel sociocultural alto (Gómez Molina, coord., 2001). 
son variantes de una sola variable, en este caso, los dos usos encontrados: cierre de unidad discursiva y ordenador del discurso, que describimos más adelante.

\subsubsection{Función}

Para justificar que estas formas se neutralizan en el discurso es preciso hallar una posición en la que sean equivalentes. Las variantes tal / y tal / o tal neutralizan sus valores en posición final, como cierre de la unidad discursiva en la que aparecen ${ }^{6}$. Algunas de las ocurrencias de esta partícula se sitúan en posición final absoluta de intervención. El resto, en posición final de acto o subacto discursivo, esto es, como cierre de una unidad informativa. Este dato será relevante a la hora de justificar los dos valores de la partícula que hemos establecido.

\subsubsection{Significado}

Siguiendo la consideración de J. Portolés (1998: 135) acerca de los marcadores del discurso, consideramos que también $/ y$ tal/ posee un valor y diversos usos ${ }^{8}$. Esa misma consideración la encontramos en L. Cortés Rodríguez, que postula que existen "diferentes valores resultado de la relación entre su significado convencional y las diversas situaciones comunicativas" (1998: 150). El valor es el propio de su categoría pronominal, tal es una proforma y por tanto, opera como sustituto de otros elementos, no solo nominales sino también de otro tipo, a saber, sintagmas adjetivales, adverbiales, e incluso oraciones completas, según el contexto lingüístico o cotexto en que aparecen. Nos interesa discutir el concepto de 'vaguedad' o 'dato de poca importancia' con que lo describe algún diccionario. L. Santos Río atribuye un significado similar a $o$ tal $^{9}$. Esto significa que el miembro que sustituye $/ \mathrm{tal}$, en cualquiera de sus variantes, pertenece al mismo paradigma de los elementos de la serie que cierra. Así en:

(1) $\mathrm{B}:\left\langle\ldots>^{10}\right.$ nos ponen primero una mesa con unos canapés y tal/ $(89 / 30 \mathrm{AP})^{11}$

(2) $\mathrm{B}:<\ldots>$ hablabas con ella/ y le rogabas para salir con ellaa para ir al cine/ para ir tal/ (302/117AP)

6 Para una revisión de las unidades discursivas que manejamos puede consultarse Briz y Grupo Val.Es.Co (2003).

7 Hemos tomado la forma /y tal/ como partícula porque es, de las tres variantes, la que mayor frecuencia de uso presenta en nuestro corpus.

8 En este trabajo empleamos indistintamente particula discursiva y marcador del discurso. Nos decantamos por el término partícula porque es el que se utiliza en el DPDE (Briz, Portolés y Pons, eds.). Esa es la denominación que elige, además, L. Santos Río (2003).

9 Dice "sirve para aportar el segundo miembro de una disyunción factual sin especificar o concretar el hecho correspondiente (dando, no obstante, a entender que se trata de un hecho parecido o asociable)", (2003: 615).

10 Las comillas angulares $(<>$ ) no figuran en el sistema de transcripción del PRESEEA ni de Val.Es.Co, las empleamos nosotros para indicar que no reproducimos toda la intervención, sino solo el fragmento que nos interesa. 11 Los valores numéricos entre paréntesis corresponden, por orden, a la página y línea en que aparece el ejemplo; los valores alfabéticos se refieren al nivel sociocultural, A (alto) o $\mathrm{M}$ (medio) y al tipo de discurso, que se ha indicado con el nombre del corpus, a saber, PRESEEA (P) y Val.Es.Co (V). El sistema de transcripción seguido por el grupo Val.Es.Co. permite una transcripción más ancha, como el que se sigue en el corpus de entrevistas, o bien, más estrecha, que es la que se emplea en el corpus de conversaciones, dadas las necesidades de cada corpus. 
En el ejemplo (1), el elemento omitido y sustituido por $/ y$ tal/ pertenece al mismo paradigma que con unos canapés, de manera que, desde un punto de vista pragmático, podemos inferir un significado del tipo "con $+X$ ", donde X expresa cualquier alimento, bebida o complemento que pueda servirse en una mesa en ese tipo de celebraciones (conocemos este contexto extralingüístico gracias al cotexto precedente explícito en la entrevista). Del mismo modo, en (2), la presencia de la preposición para anafórica, también en el miembro de cierre en que aparece $/ y \mathrm{tal} /$, nos hace pensar en otra acción que puede pedir un chico a una chica, aquí sustituye a una oración completa.

A pesar de la vaguedad que le atribuyen los autores, las intervenciones de B (que se corresponde en el PRESEEA con el informante), son -desde el punto de vista pragmáticoinformativamente completas, ya que no es necesario enumerar todos los posibles elementos que pudieran citarse, para transmitir de forma óptima lo que se está comunicando. Se podría argumentar que $/ y$ tall no concreta semánticamente pero que sí comunica de forma óptima. El valor de cierre es evidente en estos ejemplos, así como la neutralización de ambas variantes cuando ocupan la posición final de la unidad en que aparecen y van seguidas de pausa.

A la luz de estos dos ejemplos en que es evidente la alternancia de [y tal $] \sim[t a l]$, nos surge la cuestión de si el valor de cierre lo aporta, en realidad, la conjunción, o bien la partícula posee ese valor. Consideramos que $/ y$ tal/, en cualquiera de sus variantes, aparece en posición final como cierre de su unidad discursiva. Dado que habitualmente esa unidad contiene varios elementos mencionados, la conjunción une el último término y de ahí el uso frecuente de $/ y$ tal/. Pero en los casos en que se enumeran sintagmas de otro tipo como en el ejemplo (2), la presencia de " $y$ " sería agramatical, por la propia estructura sintáctica. Como el uso de $/ \mathrm{tal} /$ en la construcción (2) sigue siendo de cierre, habrá que argumentar que el valor conclusivo lo aporta $/ y$ tal/ (o sus variantes), por la posición en que se usan, y no la conjunción únicamente. Es decir, no posee el valor de cierre porque el término esté unido mediante " $y$ ", sino porque toda la forma $/ y \mathrm{tal} /$ posee dicho valor. No obstante, aunque nuestra hipótesis hasta este momento era considerar que $/ y \mathrm{tal} /$ posee un valor de cierre, éste no es el único uso que presenta, por lo que, es el momento de concretar los usos discursivos de nuestra partícula.

Como anticipábamos, será preciso recurrir a otros puntos de vista, como el pragmático, para comprender el funcionamiento de esta partícula. Para ello, acudimos a la obra de $\mathbf{J}$. Portolés (1998) pues, aunque no incluye /y tal/ en su manual, nos recuerda las funciones básicas de los marcadores del discurso. Sí la incluye L. Santos Río, que reproduce la definición del DRAE que hemos citado más arriba. También el Diccionario de particulas discursivas del español (DPDE) (Briz, 2000-2008) emplea este término y establece cuatro funciones fundamentales, a saber, conexión, modalización, focalización y control del contacto.

\subsubsection{Valores pragmáticos y discursivos}

De entre las funciones que J. Portolés establece para describir los marcadores del discurso, la partícula $/ y$ tal/ se encuadraría dentro de los "estructuradores de la información" (1998: 137). En concreto, se ubica como ordenador de la materia discursiva, pero con la

Los materiales del COVJA están, además, debidamente etiquetados. También están etiquetadas las entrevistas los del nivel sociocultural bajo (Gómez Molina, 2007), aunque estas últimas no las empleemos en este estudio. 
particularidad de que no se sitúa al principio de la secuencia, ni actúa, por tanto, como presentador de los comentarios o subcomentarios, sino que por sus características formales (morfológicas y entonativas) aparece al final de la unidad en la que opera.

Otros autores sí la han considerado como objeto de estudio. Es el caso, entre otros, de M. ${ }^{a}$ B. Alvarado Ortega, que establece tres usos o funciones para $/ y$ tall, que considera fórmula discursiva de transición (2003: 416), etiqueta tomada, a su vez, de G. Corpas (1996: 189). Su estudio se centra en la variedad recogida en el COVJA12; es, por tanto, una variedad diatópica y diastrática muy concreta pero, aún así, su análisis puede sernos muy útil y nos permitirá comparar nuestros resultados.

Según el primer uso que describe Alvarado, la partícula permite omitir la mención de ciertos elementos que se consideran consabidos puesto que pertenecen al saber compartido entre los interlocutores. El segundo tipo coincide con el que hemos expuesto hasta ahora, es decir, el uso conclusivo; y por último, un tercer valor que sirve, afirma textualmente, para "matizar el tópico conversacional", en ejemplos del tipo:

$$
\text { (3) }<E I>\text { : ¿Y en cuanto a la carrera?, los estudios } y \text { tal. }
$$

La autora explica que este tercer uso siempre aparece en posición final, y podríamos añadir que tiene un matiz casi directivo, es decir, parece en un acto iniciativo $\mathrm{y}$, por tanto, orienta una intervención de respuesta del interlocutor. Se correspondería, en nuestro corpus, con las ocurrencias del entrevistador, que generalmente formula las preguntas de forma abierta.

Aún reconociendo el interés de este matiz, nos parece que este uso se podría incluir dentro del segundo tipo, pues se conserva el valor de cierre, y como hemos avanzado, el elemento omitido pertenece al mismo paradigma que, en este caso, el sintagma los estudios. No entendemos muy bien a qué se refiere con la idea de 'matizar', ya que no es preciso mencionar el contenido que omite la partícula, pues la unidad discursiva resulta plenamente informativa, esto es, lo que el hablante comunica con $/ y \mathrm{tal} / \mathrm{es}$ el conjunto de aspectos afines que el interlocutor puede comentar a propósito de ese tema, de modo que se podría parafrasear como: ¿Y en cuanto a la carrera?, los estudios "y las demás cosas que consideres relevantes o simplemente interesantes que quieras contarme al respecto". E1 interlocutor no precisa que se verbalicen esos datos, puesto que el valor pronominal subyacente de la partícula sustituye contenidos del mismo nivel paradigmático.

Este mismo argumento puede aplicarse también al primer tipo. Efectivamente, es el saber compartido el que posibilita la omisión de más detalles, de ahí que la intervención sea plenamente informativa. En el caso de las entrevistas del PRESEEA, no existe ese saber compartido porque los participantes del acto comunicativo son generalmente desconocidos y su función la suple el cotexto de la conversación precedente.

12 Dirigido por D. Azorín y J. L. Jiménez (1997): Corpus oral de la variedad juvenil universitaria del español hablado de Alicante, Alicante, Instituto de Cultura Juan Gil-Albert.

13 Aplicamos la teoría de las unidades de Briz y otros (2003) en la descripción de todas las ocurrencias, tanto de las entrevistas como de las conversaciones.

14 Según el sistema de transcripción empleado, los corchetes seleccionan un fragmento de discurso en el que se produce solapamiento, es decir, el habla simultánea de los dos participantes. 
M. Belén Alvarado también recoge las descripciones de L. Ruiz y de G. Corpas. Por un lado, L. Ruiz considera que $/ y$ tal/ es una fórmula rutinaria, en concreto, una fórmula discursiva de transición. En este grupo se incluyen los llamados gambitos ("unidades que se especializan en señalar cambios de nivel en la conversación o en preparar a los interlocutores para el turno siguiente", 1998: 49). Entre ellos, "y eso, y tal, que constituyen cierres enumerativos". En un trabajo anterior lo consideraba

marcador del enunciado con valor continuativo que puede actuar en el interior de un acto, [...] se convierte en un Lugar de Transición Pertinente que puede ser aprovechado por el receptor o reutilizado por el emisor para prolongar su turno. [...] Para el emisor constituye un apoyo fático mientras que el receptor lo entiende como un LTP. (1996: 496-7)

es decir, hacía mención a su posición (interior o no) y, de manera implícita, se refería a dos funciones cierre (cesión del turno) o pre-cierre (uso continuativo), semejantes a las que en este trabajo hemos establecido.

Precisamente, las ocurrencias correspondientes al entrevistador, que hemos mencionado más arriba, gracias a la entonación y al uso de esta partícula en posición final, constituyen un acto iniciativo (desde el punto de vista de la estructura de la conversación) ${ }^{13}$. Es decir, le indican al interlocutor la cesión del turno de habla, que en la entrevista sí está predeterminado, a diferencia de la conversación libre. El siguiente ejemplo pertenece al entrevistador y demuestra ese matiz directivo:

(4) A: pues como jobi $[y$ tal]14 (375/250AP) (E)

En los demás casos de $/ y$ tal/ en posición final de intervención, el hablante parece querer expresar con la partícula un contenido informativo del tipo " $y$ no sé qué más contarte al respecto". Por tanto, es casi una forma de ceder el turno, pero solo en caso de aparecer en posición final absoluta de intervención. Hay que tener en cuenta que en un acto puede haber una enumeración (como en el ejemplo anterior) o bien puede haber un conjunto de actos enumerados, como en (5):

(5) B: iremos a cenaar/ saldremos por ahí a tomarnos algunas copas por los pafs $\mathrm{s}^{15 /}$ y tal (372/137MP)

Por su parte, G. Corpas resume varias clasificaciones de unidades fraseológicas antes de ofrecer la suya propia. Según su criterio, estas fórmulas discursivas forman parte de los enunciados fraseológicos (o fórmulas rutinarias), que pertenecen al acervo sociocultural de los hablantes, es decir, están fijadas en el habla.

Si estas autoras estudian (o incluyen) nuestra partícula en sus manuales sobre fraseología, significa que existe entre sus componentes un alto grado de fijación. Eso implica que forman una unidad, y los dos miembros aparecerán siempre unidos sin ningún elemento incrustado, como en el caso de $/ y$ tall. En caso contrario, la partícula estaría todavía en proceso de fijación. Así creemos que sucede con /o tall, pues encontramos la forma $o$ más tal con valor de cierre, como variante de $/ y$ tall:

15 Del inglés pubs. 
(6) B: cuando hacemos un viajee- fuera un viaje máas- más largoo o más tal peroo en cuanto a/ mm/ cambiar de vida/ ee/ bueno/ (260/503AP)

Esta es una ocurrencia aislada, de manera que no nos parece relevante en nuestro estudio. Si la hemos incluido es porque nos demuestra, una vez más, que el valor conclusivo no lo aporta la conjunción " $y$ " que, según la gramática, enlaza el último miembro de una enumeración como cierre; sino que tal en posición final posee ese valor discursivo, y que la presencia de las conjunciones $y / o$, así como cualquier otro elemento necesario para que el enunciado sea gramatical (como la preposición para en el ejemplo (2) visto más arriba), se justifica por la propia estructura sintáctica de la unidad del discurso en la que aparece la partícula.

Más recientemente, $M{ }^{a}{ }^{a} B$. Alvarado (2008) realiza una propuesta de clasificación de fórmulas discursivas (FR), como tipo de enunciados fraseológicos, dentro de la categoría más general unidad fraseológica (UF) e incluye y tal en el grupo de fórmulas discursivas de transición "que sirven para suprimir información", junto a otras fórmulas como no sé qué no sé cuántos, y eso (2008: 325). También indica que en determinados contextos puede alternar con y eso. En este trabajo, al incluir y tal en un estudio completo sobre FR, justifica sus propiedades como UF: idiomaticidad, fijación, independencia, que, sin embargo, en las FR discursivas no siempre se cumplen, ya que se encuentran más cerca de la categoría marcador del discurso que de la categoría UF. La identificación de ambas categorías es explicable puesto que comparten ciertos rasgos: un marcador del discurso también es una unidad fija, por ejemplo, en virtud de su mayor o menor grado de gramaticalización. En concreto, afirma que en las FR discursivas "la fijación semántico-pragmática no es obligatoria" (2008: 107), ya que sus funciones dependen del contexto. En nuestra opinión, las funciones de los marcadores dependen, en gran medida, de su posición discursiva (posición en unidades del discurso), como ya hemos defendido con anterioridad (Montañez Mesas, 2007a y 2007b). Según Alvarado tampoco poseen independencia (entonativa ni distribucional) ${ }^{16}$.

La propia autora reconoce que ciertos "valores discursivos se aproximan a la función que tienen los marcadores argumentativos en la conversación" (2008: 396), puesto que no cumplen todas las características y "su función es semejante a la que realizan los marcadores argumentativos, ya que guían al oyente para que interprete adecuadamente el enunciado". Sin embargo, dado que esta partícula "no funciona siempre de manera prototípica como un marcador discursivo", y gracias a su independencia y a que pueden distinguirse dos valores en la conversación ("suprime conocimientos socioculturales que el hablante supone que son compartidos por su interlocutor" y "valor conclusivo de intervención"), le permiten afirmar que es una FR discursiva (Ibid., 396-7).

Lo novedoso de la propuesta de M. ${ }^{a}$ B. Alvarado (2008) es el hecho de que se base en la modalidad del enunciado y de que metodológicamente aplique, al igual que nosotros, el modelo de segmentación del grupo Val.Es.Co. para identificar el tipo de unidad que constituye la FR.

Desde otra perspectiva, A. Briz (1998) distingue entre conectores pragmáticos y conectores metadiscursivos. Dentro de estos últimos, incluye las marcas de cierre, entre las que situamos nuestra partícula. Este autor los vincula a la actividad argumentativa, mientras que,

16 En concreto, y tal "no podría haber cambiado su orden en la intervención, ni se podría haber dicho varias veces" (2008: 124). 
en nuestro caso, consideramos que $/ y$ tal/ no persigue una estrategia argumentativa, sino metadiscursiva: el cierre de la secuencia o unidad discursiva en la que aparece, sea definitivo ese cierre o no. Es necesario aclarar este aspecto, y eso nos lleva a comentar los usos discursivos de $/ y$ tal/ que hemos establecido a partir del análisis de nuestro corpus:

a) cierre, uso conclusivo (en posición final de intervención o acto): /y tal//

b) ordenador ${ }^{17}$ o espaciador de la materia discursiva, sea narrativa, explicativa, descriptiva... Es un falso cierre o cierre momentáneo, y por tanto, se convierte en un uso ordenador, en final de acto o dentro de este: $/ y$ tal $_{2} /$

En el primer caso (cierre), la partícula no necesariamente ha de estar en posición final de intervención, sino que también puede cerrar un acto, unidad aislable que puede constituir intervención por sí misma (Briz y otros, 2003: 14). La marca lingüística que permite identificar el valor conclusivo es la presencia de una pausa (de duración variable) que indica el límite entre unidades significativas (no en vano una de las funciones de la entonación y de las pausas es la función demarcativa). Así, en (7) el hablante cierra el acto "no hay que hacer ningún cálculo ningún acceso a disco" con la partícula y, tras la pausa, añade un nuevo acto:

(7) $\mathrm{A}:<\ldots>$ una operación de estas que consiste prácticamente enn traerte la pantalla y ya estáa/ no hay que hacer ningún cálculo ningún acceso a disco y tal// y te quedabas veinte y treinta segundos esperando $<\ldots>(339 / 131 \mathrm{AV})$

En cambio, en otros casos, el hablante no cierra el acto, sino que la partícula puede ir seguida de otros elementos, estructuralmente subactos, que aclaran, concretan o repiten algo de lo dicho, por lo que el valor es de falso cierre o cierre momentáneo, esto es, y tal presenta un uso continuativo, como en (8):

(8) B: $<\ldots>$ ese cuarto de hora de son ocho menos cuarto yo me levanto a las ocho/ entonces pues $\mathrm{m}(\mathrm{e})$ afeito me aseo $\mathbf{y} \mathbf{t a l} /$ desayuno/ porque ya desayuno $<\ldots>(470 / 186 \mathrm{MP})$

En este ejemplo el hablante añade un subacto más al mismo acto " $m(e)$ afeito me aseo y tal/ desayuno", no un acto distinto. Por tanto, el uso ordenador de $/ y$ tal/, que llamamos ly tal $\mathrm{l}_{2}$, no se caracteriza por su posición intermedia en el discurso, puesto que suele ir seguido de pausa, sino que se define porque a pesar de llevar, en ocasiones, esa pausa, no cierra la unidad, sino que es un falso cierre, una conclusión momentánea, que permite al hablante anadir más elementos posteriormente; se convierte en un uso ordenador, e incluso, retardatario. La ventaja del discurso hablado es que a pesar de introducir fórmulas de cierre, el hablante puede añadir cuantas ideas quiera sin acusar problemas en la comunicación. En esa línea, Corpas postula que estas secuencias

facilitan un rápido procesamiento del lenguaje, de forma que los hablantes pueden dedicar más tiempo a planificar unidades del discurso más largas y a cuidar los aspectos sociales de la comunicación (1998: 173) $)^{18}$.

17 Nombre tomado de J. Portolés (1998: 138).

18 Ese valor social de las FR también lo recoge Alvarado (2008: 335). 
En el siguiente ejemplo aparece seguido de pausa y corresponde a un $/ y t a l_{2} /$, es decir, es un cierre momentáneo que, no obstante, permite al hablante añadir más elementos $a$ posteriori:

(9) yy nada vinieron un banquetee/ un cáterin para la cena un cáterin y tal/muy bien/ una orquestaa/ (396/281AP)

El uso ordenador de $/ y \mathrm{tal} /$ es propio del discurso dialogal ${ }^{19}$, al que corresponden tanto el corpus de entrevistas del PRESEEA, como las conversaciones contenidas en el corpus de Val.Es.Co., que recogen dos tipos de interacciones in praesentia física de los interlocutores (cara a cara), consideradas ambas como pertenecientes al nivel conversacional. La forma $/ y \mathrm{tal} /$ es una consecuencia más de uno de los factores primarios de la conversación coloquial: la planificación sobre la marcha, ya que mientras que el entrevistador tiene preparadas las cuestiones y el orden de la entrevista, el informante ha de planificar sobre la marcha sus respuestas. Este rasgo coincide, en parte, con la descripción de M. Seco cuando habla de 'vaguedad', o con la imprecisión a la que alude la Academia, pues aunque la intervención no concreta algunos elementos (porque se omiten), resulta plenamente informativa.

Así, siguiendo con el apartado anterior, según la caracterización de A. Briz, la estrategia que persigue esta partícula es metadiscursiva, por un lado, elude la mención de más elementos que completen de forma exhaustiva el discurso del hablante; y por otro lado, /y $\mathrm{tal}_{2} /$ cierra momentáneamente la unidad discursiva mientras se planifica la adición de más elementos que se consideran pertinentes.

Aunque hemos establecido que la marca que nos permite justificar la neutralización es la pausa, no es ese el único contorno que permite establecer sus valores, pero sí en el que se produce la alternancia o variación de forma sistemática. En algunas ocurrencias no hay pausa y también hay cierre, como en los casos que siguen:

(10) B: y nada más entrar pues nos dan/ el cambio/ el jefe y tal que no tenemos que llevar a la vía// (331/131MP)

(11) B: y es un pueblo pequeñito/ que en invierno creo que vive/// (3") $)^{20}$ entre Rogelio y tal son treinta y cinco habitantes/ (362/562MP)

También puede suceder lo contrario, que una forma tenga pausa y sin embargo, no tenga valor discursivo de cierre:

(12) B: uunnos platos// combinados// con ensalada/ yy algo de carne/// y ya después pues nada el postre yy tal/ con algún adornito pero vamos// (180/213MP)

(13) B: yo las que suelo hacer siempre/ son las dee ee acción/las de soldados/bélicas y tal/ aviones barcos/ (351/167MP)

19 En este trabajo utilizamos dialogal y dialógico indistintamente, a pesar de las diferencias que establece, entre otros, J. Moeschler (1985): Argumentation et conversation. Eléments pour une analyse pragmatique du discours, Université de Genève, Hatier-Credif, p. 93.

20 Este paréntesis indica que la duración de la pausa es de tres segundos. 
Hay que hacer notar, antes de proseguir, que toda esta explicación teórica no se contradice con la propuesta de este estudio que es considerar la neutralización funcional de /tal/e ly tal/, ya que mientras que en la descripción de la partícula se han tenido en cuenta todas las ocurrencias, en el análisis de la alternancia solo se han incluido aquellas que manifiestan neutralización entre variantes, cuya marca es ir seguidas de pausa y situarse en posición final de la unidad en la que aparecen.

No queremos avanzar este estudio sin antes hacer mención de una serie de formas lingüisticas que también aparecen en posición final en nuestro corpus y que igualmente poseen la función de cierre: y nada, y eso, y ya está ${ }^{21}$. Muchas de ellas las analizan G. Corpas (1996), L. Ruiz Gurillo (1998) o M. ${ }^{a}$ B. Alvarado (2008).

\subsection{Hipótesis de partida}

Una vez analizados los usos de esta partícula, nos adentramos ya en el análisis. El estudio que presentamos se sitúa en un tiempo aparente, pertenece a un momento sincrónico, pero refleja un tiempo aparente por las edades de los informantes, esto es, analizamos las muestras de una comunidad de habla en un momento dado. Para que los resultados se correspondieran con un tiempo real, habría que realizar la misma investigación en un intervalo de tiempo de treinta o cuarenta años para observar la evolución de este fenómeno.

La hipótesis de la que partimos es la de la posible variación intraidiomática y neutralización de las formas $/ \mathrm{tal} / \mathrm{y} / \mathrm{y}$ tal/ en el español hablado de Valencia en dos corpus: El español hablado de Valencia, dentro del PRESEEA (Proyecto para el estudio sociolingüístico del español de España y América) y el Corpus de conversaciones coloquiales, del Grupo Val. Es.Co (Valencia Español Coloquial), que a continuación comentamos.

\section{Aclaraciones metodológicas}

\subsection{Corpus}

El corpus del que parte este estudio consta, por un lado, de 48 entrevistas realizadas en la ciudad de Valencia, 24 para el nivel sociocultural alto, recogidas durante el periodo de 1996 a 2000, y 24 para el nivel sociocultural medio (1999-2002), publicadas por la Universitat de València (Gómez Molina, 2001 y 2005). Al tratarse de un corpus de entrevistas, la estructura está claramente definida por el esquema pregunta-respuesta. Se trata de entrevistas semidirigidas, pues el investigador-entrevistador aplica una encuesta previa, aunque no de forma estricta, pues a lo largo de la entrevista la actitud y cooperación del informante pueden alterar ese esquema previo $^{22}$. Este género discursivo tiene la ventaja de que las cuestio-

21 Del mismo modo, algunas de ellas presentan variantes y podrían ser objeto de un estudio posterior: $y$ eso (eso, y todo eso, todo eso, y eso si, pues eso, ni eso, o eso); y nada (y nada más, ni nada, nada, pues nada, entonces nada); entonces (entonces si); y todo; y punto; y asi (o así); o algo (o algo asi); etcétera (etecé, y etcétera, etcétera etcétera); y poco más; $y$ demás; y esas cosas ( $y$ to(d)as esas cosas, y todas las cosas, y estas cosas, y cosas asi, o cosas así, o una cosa así, y cosas de esas, ni cosas de esas, o cosas de esas); vamos (pero vamos); pero bueno (pero bueno bien), y no sé que, y chimpún, y se acabó, y patatín y patatán.

22 En la introducción del corpus se caracteriza como habla espontánea preparada (2005: 29), porque a pesar de que las preguntas están preparadas, gran parte de la interacción es espontánea. 
nes previstas por el investigador están pensadas para seleccionar determinadas ocurrencias lingüísticas que sirvan de objeto de estudio posterior: secuencias narrativas, expresiones de futuro, expresión de hipótesis, secuencias argumentativas, entre otras ${ }^{23}$.

Por otro lado, dado que entre los factores que hemos manejado están el tipo de secuencia y el registro en el que aparece $/ y \mathrm{tal} /$, nos parecía interesante cotejar los resultados obtenidos con los de otro corpus de referencia de otro género discursivo: la conversación, en concreto, la conversación coloquial (Briz y grupo Val.Es.Co., 2002). Para que los datos fueran coherentes hemos seleccionado únicamente las conversaciones entre hablantes de estrato sociocultural alto y medio. Son 6 conversaciones obtenidas mediante grabación secreta en las que el investigador actúa de observador participante.

La interacción de los resultados de ambos corpus es muy significativa pues, por un lado, el corpus de Val.Es.Co recoge conversaciones coloquiales, con unas características claramente definidas (ausencia de planificación o planificación sobre la marcha, relación de proximidad entre los interlocutores, alternancia de turno no predeterminada), mientras que el PRESEEA es un corpus de entrevistas semidirigidas, con un plan previo de cuestiones que se repiten en todos los informantes y que pretenden seleccionar una serie de resultados lingüísticos, es decir, cada pregunta persigue unos datos concretos. También posee unas cualidades propias, pues la alternancia de turno y los papeles comunicativos están determinados desde el principio, el espacio está marcado y no siempre se establece una relación de proximidad, todo el saber compartido se reduce a la conversación que comparten durante la presentación (realizada por un tercer participante que asiste de oyente) y la propia entrevista.

\subsection{Variables lingüísticas y sociológicas}

En el análisis de esta partícula, hemos establecido una serie de parámetros que nos han parecido relevantes durante la selección de las ocurrencias. En primer lugar, los factores sociológicos a los que vamos a atender son: sexo, edad, nivel sociocultural (medio y alto) y lengua habitual. Entre los parámetros estrictamente lingüísticos hemos establecido: tipo o uso específico de la partícula (valor pragmático), tipo de secuencia (valor estilístico), cotexto lingüístico (orden sintagmático) y registro (variable estilística).

Es preciso aclarar estos últimos valores. Por un lado, consideramos, del mismo modo que hace J. Portolés en su manual sobre marcadores (1998), que la forma $/ y \mathrm{tal} /$, como marcador, posee un valor y varios usos. El valor gramatical es indefinido o pronominal, como hemos aclarado. Ese valor subyace en todos los ejemplos, mucho más evidente cuando la partícula va acompañada de una preposición o cuando sustituye a otro elemento con el que se coordina mediante la conjunción ' $y$ '. Lo que sí varía es el uso, que se establece según el contexto sintagmático y la secuencia discursiva en la que aparece el ejemplo. El orden sintagmático se observa en el ejemplo de cada ocurrencia, que hemos reproducido, y los tipos de secuencia en los que puede aparecer son: expositivo, argumentativo, narrativo, instructivo o directivo y predictivo. Dentro del tipo expositivo queda englobada tanto la enumeración como la descripción. La enumeración puede ser de dos miembros (coordinación) o bien

23 Para una revisión más completa de las directrices que han operado en la elaboración del corpus (delimitación de la comunidad de habla, selección de los informantes, tipo de transcripción, estructura y contenido de la entrevista), puede consultarse la amplia introducción de dichos corpora (Gómez Molina, 2001 y 2005). 
concluir la mención de más de dos elementos, como en el caso que sigue, en el que /y tal/ constituye un cierre enumerativo:

(14) B: pues eso/ bioquímicaa/ química orgánicaa ee etcétera etcétera/ fisiologías y tal/ (99/397AP)

Por otro lado, consideramos que el registro en las entrevistas es [+neutro], mientras que en la conversación cotidiana es claramente [+coloquial o informal], debido a la existencia de rasgos coloquializadores no presentes en la mayoría de entrevistas de este corpus: relación vivencial de proximidad entre los interlocutores y, por tanto, saber compartido; marco espacial no marcado (las entrevistas se realizan, por lo general, en el despacho del investigador), y relación funcional de igualdad (los papeles comunicativos están fijados de antemano y, con ello, la alternancia de turnos). Por todo ello, a pesar del carácter dialógico de ambos discursos, las diferencias situacionales justifican el interés por compararlos y contrastar los usos de esta partícula, y de cualquier otro elemento, en ambos corpus.

\section{Estudio descriptivo}

En el estudio de esta partícula hemos considerado pertinentes tres fases, a saber, observación, descripción y explicación de su funcionamiento y de la posible neutralización de sus variantes en una determinada posición sintagmática.

\subsection{Observación}

Una vez seleccionado el corpus, hemos procedido a localizar las muestras en que aparecían empleadas las formas $/ \mathrm{tal} / \mathrm{y} \mathrm{tal} / \mathrm{y} / \mathrm{o} \mathrm{tal} / \mathrm{y}$ a ordenarlas en fichas, junto al contexto de uso en que aparecian, para poder determinar la función o funciones pragmadiscursivas que presentan en el español hablado de Valencia.

En cuanto a la selección de las ocurrencias, no se evidencia un uso generalizado de esta partícula en todos los informantes: algunos la emplean de forma sistemática, y otros no la utilizan en ningún caso. También hemos recogido las ocurrencias pertenecientes al investigador-entrevistador, aunque no podemos perder de vista su papel comunicativo, ya que es evidente que su posición de entrevistador condiciona la estructura de sus intervenciones, interrogativas en su mayoría, es decir, actos directivos.

\subsection{Descripción}

El estudio descriptivo de esta partícula presenta dos facetas que tenemos en cuenta: una cualitativa y otra cuantitativa. En el primer caso, es preciso, antes de nada, identificar la variable que hemos observado en la comunidad de habla del área metropolitana de Valencia (el uso conclusivo de $/ y$ tal $/$ ), así como sus variantes $(/ t a l /$ y $/ o$ tall). El contexto lingüístico que hemos identificado como pertinente es la posición final de la unidad en la que opera la partícula, cuyo contorno es, sencillamente, aparecer seguida de una pausa fónica.

El diseño cualitativo integra una serie de variables sociológicas que hemos enumerado en el apartado anterior: edad, sexo, nivel sociocultural y lengua habitual. La elección de 
estas variables sirve para caracterizar a la población y nos permite establecer si hay preferencias en el uso de la partícula en función de alguno de esos parámetros. Estos datos figuran en una ficha técnica del informante que se publica junto a cada entrevista y que sirve al investigador para clasificar los datos obtenidos. En las conversaciones de Val. Es.Co también se incluye una ficha con las características sociológicas de los participantes, por lo que el cotejo de ambos corpus no solo es posible, sino perfectamente válido y los resultados, coherentes. A la hora de representar los datos es necesario codificarlos para que su visualización sea más sencilla y puedan, a su vez, ser procesados por los programas estadísticos correspondientes.

En nuestro análisis hemos codificado las variantes asignando un valor numérico a cada una de las opciones de cada factor sociológico o lingǘstico, p. ej. en el factor 'sexo', (1) corresponde a 'hombre', y (2) a 'mujer', como muestra el siguiente cuadro:

\begin{tabular}{|c|c|c|c|c|c|}
\hline Factores & 1 & 2 & 3 & 4 & 5 \\
\hline $\begin{array}{l}\text { Usos de la partícula (valor } \\
\text { pragmático) }\end{array}$ & $\begin{array}{l}\text { /y tal/1 } \\
\text { [cierre] }\end{array}$ & $\begin{array}{c}\text { ly } \mathbf{t a l}_{2} \\
\text { [ordenador] }\end{array}$ & & & \\
\hline $\begin{array}{l}\text { Tipo de secuencia discursiva } \\
\text { (valor estilistico) }\end{array}$ & expositiva & argumentativa & narrativa & instructiva & predictiva \\
\hline Sexo & hombre & mujer & & & \\
\hline Edad & $<35$ años & $35-55$ & $>55$ & & \\
\hline Lengua habitual & castellano & bilingüe & valenciano ${ }^{24}$ & & \\
\hline Nivel sociocultural & alto & medio & & & \\
\hline Registro & {$[+$ neutro $]$} & {$[+ \text { coloquial }]^{25}$} & & : & \\
\hline
\end{tabular}

En la base de datos que manejamos, se han codificado, además, otros datos: se ha añadido una columna referida, por un lado, a la localización de la muestra, con indicación, como en los ejemplos, de la página y línea en que pueden consultarse. En caso de aparecer más de una ocurrencia en la misma línea, se ha marcado con caracteres alfabéticos en letra minúscula $(a, b, \ldots)$. Por otro lado, hemos establecido subtipos en las secuencias de tipo narrativo, y aunque no los hemos considerado parámetros o factores pertinentes en el estudio de la variación, sí los hemos tenido en cuenta en la descripción. Por ello, en la misma columna indicamos si se trata de una ocurrencia extraída de un relato conversacional, y si corresponde a la voz propia del informante o a una voz ajena. Para ello se han empleado

24 Catalán en su variedad dialectal 'valenciano'.

25 Entendemos que la variación diafásica es gradual y, por tanto, lo expresamos en términos de \pm , ya que son diversos los factores que determinan el grado de coloquialidad de un discurso, sea este una entrevista, sea un conversación cotidiana... Para una revisión de estos factores o rasgos coloquializadores, descritos por A. Briz y el grupo Val.Es.Co. puede consultarse tanto en el corpus de conversaciones (Briz y grupo Val.Es.Co., 2002), como en el manual de español coloquial donde se sistematizan los presupuestos teóricos y prácticos sobre el uso coloquial en la conversación, pero aplicables a cualquier tipo de discurso (Briz, 1998). 
las abreviaturas que siguen: relato conversacional con voz propia (rel.v.p.) y relato conversacional con voz ajena (rel.v.a.). En este mismo apartado se ha especificado entre paréntesis si se trataba de muestras del entrevistador $(E)$ y si aparecían en posición final absoluta de intervención ( $p . f$.).

Como se apuntó en el apartado teórico, en la Universidad de Alicante se ha elaborado un estudio semejante a partir de un corpus sobre el español hablado de Alicante, el COVIA, que forma parte del ALCORE, Alicante Corpus del Español. De forma teórica y humildemente preliminar hemos comparado los usos que se atribuyen a $/ y$ tal/ en ese corpus y en el nuestro, aplicado al español hablado de Valencia (completado con el corpus de conversaciones referidas al español hablado en Valencia).

Por el momento, ofrecemos un cuadro-resumen con los datos obtenidos. En nuestro estudio hemos encontrado 210 ocurrencias, que hemos ordenado según los factores establecidos. De esas muestras, 174 corresponden al uso como cierre (al que hemos asignado el subíndice 1) y 36 al uso ordenador (que hemos denominado $/ y$ tal $f_{z}$ ). La variación, como hemos señalado, se produce en el uso conclusivo de y tal (y tal, ), por lo que ofrecemos solamente los datos referidos a ese uso de cierre $\left(y\right.$ tal $\left._{l}\right)$ :

CUADro 1. La forma y tal en el español hablado de Valencia.

\begin{tabular}{|c|c|c|c|c|c|}
\hline Factores & $\begin{array}{l}\text { /y tal } \\
\mathbf{1 7 4}\end{array}$ & & & & \\
\hline Variantes & $\begin{array}{l}\text { y tall } \\
\mathbf{1 2 8}\end{array}$ & $\begin{array}{l}\text { Itall } \\
\mathbf{4 0}\end{array}$ & $\begin{array}{c}10 \text { tall } \\
6\end{array}$ & & \\
\hline $\begin{array}{l}\text { Tipo de secuencia discursiva } \\
\text { (valor estilistico) }\end{array}$ & $\begin{array}{c}\text { expositiva } \\
93\end{array}$ & $\begin{array}{l}\text { argumentativa } \\
\mathbf{2 8}\end{array}$ & $\begin{array}{c}\text { narrativa } \\
44\end{array}$ & $\begin{array}{l}\text { instructiva } \\
\mathbf{5}\end{array}$ & $\begin{array}{c}\text { predictiva } \\
\mathbf{4}\end{array}$ \\
\hline Sexo & $\begin{array}{c}\text { hombre } \\
\mathbf{1 2 3}\end{array}$ & $\begin{array}{c}\text { mujer } \\
\mathbf{5 1}\end{array}$ & & & \\
\hline Edad & $\begin{array}{l}<35 \text { años } \\
\mathbf{5 7}\end{array}$ & $\begin{array}{c}35-55 \\
\mathbf{8 6} \\
\end{array}$ & $\begin{array}{c}>55 \\
\mathbf{3 1}\end{array}$ & & \\
\hline Lengua habitual & $\begin{array}{c}\text { castellano } \\
91\end{array}$ & $\begin{array}{l}\text { bilingüe } \\
\mathbf{3 4}\end{array}$ & $\begin{array}{c}\text { valenciano }^{26} \\
49\end{array}$ & & \\
\hline Nivel sociocultural & $\begin{array}{c}\text { alto } \\
84\end{array}$ & $\begin{array}{c}\text { medio } \\
\mathbf{9 0}\end{array}$ & & & \\
\hline Registro & $\begin{array}{c}\text { neutro } \\
169\end{array}$ & $\begin{array}{c}\text { coloquial } \\
5\end{array}$ & & & \\
\hline
\end{tabular}

Una vez observados los datos, se detecta que el uso más frecuente de la partícula / y tal/ es el conclusivo, que también se manifiesta cuando la partícula aparece sin la conjunción ' $y$ ' $o$ cuando se usa con otra conjunción ' $o$ '. El dato más llamativo lo encontramos en el factor

26 Catalán en su variedad dialectal 'valenciano'. 
de registro: según los datos obtenidos, el uso de la partícula /y tal/ es mucho más frecuente en las entrevistas semidirigidas, en las que hay un registro más neutro, que en las conversaciones coloquiales, donde el registro es más informal. Sin embargo, no podemos olvidar la diferencia en la extensión del corpus: mientras que las entrevistas del PRESEEA son 48, las conversaciones de Val.Es.Co que corresponden al nivel alto y medio son únicamente 6 , y también es menor su duración con respecto a aquellas.

\subsection{Explicación}

Tras revisar y analizar detenidamente los contextos de uso de la forma $/ y$ tal/ en este corpus, observamos que se utiliza con dos funciones, a saber, conclusiva o de cierre y ordenadora de la materia discursiva. Asimismo, detectamos dos formas semejantes, /tal/ y /o tal/ que, cuando les sigue una pausa, comparten ese valor conclusivo con $/ y$ tal/. Este dato nos lleva a proponer que la partícula $/ y$ tal $/$, con valor de cierre, presenta variación en el español hablado de Valencia cuando va seguida de pausa. Sus variantes son /tall y /o tall. Esta variación se produce con $/ y \mathrm{tal}_{l} /$, mientras que $/ y \mathrm{tal}_{2} /$ varía con $/$ tall, pero no con $/ o$ tall, que solo se utiliza como cierre en nuestro corpus.

\section{Conclusiones}

La partícula /y tall presenta en el corpus del español hablado de Valencia dos usos discursivos, a saber, cierre de la unidad discursiva en que aparece (subacto, acto o intervención), y ordenador de la materia discursiva, en secuencias textuales de diversos tipos: expositivas, argumentativas, narrativas, predictivas e instructivas. En el valor pragmático conclusivo, alterna con $/$ tal/ y lo tall, de manera que sus contenidos semántico y discursivo se neutralizan. En el uso ordenador o estructurador, la variación se establece entre /tall y /y tall. La posición sintagmática que revela dicha neutralización entre las variantes de la variable cierre es la posición final de la unidad discursiva, cuando fónicamente la partícula va seguida de pausa. El valor de $/ y \mathrm{tal} /$, que es como hemos denominado al uso conclusivo, no lo aporta la conjunción, sino que la partícula se ha fijado con esa función y su frecuencia de aparición es mucho mayor que /tall.

Los usos de $/ y$ tall que hemos consignado se refieren al español hablado, en situaciones en que el hablante planifica sobre la marcha, de modo que, en el caso de $/ y$ tal $/$, la partícula concluye sin precisar ni especificar más contenidos que pudiera añadir y con $/ y$ tal $_{2}$, concluye momentáneamente mientras planifica otro miembro del discurso, de manera que la partícula le permite ordenar el pensamiento y formular lo que sigue. Este rasgo es el que justifica la presencia de $/ y$ tal/ en estos dos usos, pues en otro tipo de discurso evidenciaría una elaboración escasa o deficiente.

En sintesis, la partícula /y tall, situada en posición final de la unidad del discurso a la que acompaña, permite al hablante concluir un enunciado indicando a su interlocutor la cesión en el turno de habla y comunicándole a su vez, mediante una serie de inferencias pragmáticas y del saber compartido, un contenido fácil de reconstruir y tal. 


\section{Apéndice. Sistema de transcripción del grupo Val.Es.Co. ${ }^{* 27}$}

A:
$?:$
$\S$
$=$
[
]
/
$1 /$
$/ 1 /$

Cambio de voz.

Intervención de un interlocutor identificado como A.

Interlocutor no reconocido.

Sucesión inmediata, sin pausa apreciable, entre dos emisiones de distintos interlocutores.

Mantenimiento del turno de un participante en un solapamiento.

Lugar donde se inicia un solapamiento o superposición.

Final del habla simultánea.

Reinicios y autointerrupciones sin pausa.

Pausa corta, inferior al medio segundo.

Pausa entre medio segundo y un segundo.

Pausa de un segundo o más.

Silencio (lapso o intervalo) de 5 segundos; se indica el $\mathrm{n}^{\mathrm{o}}$ de segundos en las pausas de más de un segundo, cuando sea especialmente significativo.

Entonación ascendente.

Entonación descendente.

Entonación mantenida o suspendida.

Cou Los nombres propios, apodos, siglas y marcas, excepto las convertidas en «palabras-marca» de uso general, aparecen con la letra inicial en mayúscula.

PESADO

pe sa do

Pronunciación marcada o enfática (dos o más letras mayúsculas).

(())

((siempre))

$((\ldots))$

(en)tonces

pa'l

${ }^{\circ}()^{\circ}$

$\mathrm{h}$ Pronunciación silabeada.

Fragmento indescifrable.

Transcripción dudosa.

Interrupciones de la grabación o de la transcripción.

Reconstrucción de una unidad léxica que se ha pronunciado incompleta, cuando pueda perturbar la comprensión.

Fenómenos de fonética sintáctica entre palabras, especialmente marcados.

Fragmento pronunciado con una intensidad baja o próxima al susurro.

Aspiración de «s» implosiva.

(RISAS, TOSES, Aparecen al margen de los enunciados. En el caso de las risas, si son simultáneas GRITOS...)

\section{aa}

a lo dicho, se transcribe el enunciado y en nota al pie se indica «entre risas».

Alargamientos vocálicos.

$\mathrm{nn}$

ii!?

Alargamientos consonánticos.

Interrogaciones exclamativas.

¿?

i!

Interrogaciones. También para los apéndices del tipo «¿no?, ¿eh?, ¿sabes?»

Exclamaciones.

és que se pareix

Fragmento de conversación en valenciano. Se acompaña de una nota donde se a mosatros:

Letra cursiva: traduce su contenido al castellano.

Reproducción e imitación de emisiones. Estilo directo, característico de los denominados relatos conversacionales.

\footnotetext{
* Las incorrecciones gramaticales (fónicas, morfosintácticas y léxicas) no aparecen marcadas por lo general. Así pues, según el usuario del corpus (p. e., si este es utilizado por un estudiante de español como segunda lengua), puede ser recomendable el soporte explicativo del profesor.

** Los antropónimos y topónimos no se corresponden por lo general con los reales.

27 Para una revisión y desarrollo de las convenciones seguidas por Briz y grupo Val.Es.Co. puede consultarse la edición del (2002a: 29-36) y en el artículo Briz Gómez, A. y Grupo Val.Es.Co. (2002b): "La transcripción de la lengua hablada: el sistema del grupo Val.Es.Co.", Español Actual, 77-78, 57-85.
} 
Notas a pie de de página:
Anotaciones pragmáticas que ofrecen información sobre las circunstancias la enunciación Rasgos complementarios del canal verbal. Añaden informaciones necesarias para la correcta interpretación de determinadas palabras (la correspondencia extranjera de la palabra transcrita en el texto de acuerdo con la pronunciación real, siglas, marcas, etc.), enunciados o secuencias del texto (p. e., los irónicos), de algunas onomatopeyas; del comienzo de las escisiones conversacionales, etc.

\section{Referencias bibliográficas}

Alcina, J.-Blecua, J. M.a (2001): Gramática española, Barcelona, Ariel, $11^{\text {a }}$ ed., [1 $\left.1^{\mathrm{a}} \mathrm{ed} .1975\right], 679-682$. Alvarado Ortega, M. ${ }^{a}$ B. (2003): "Las fórmulas discursivas de transición en la variedad juvenil universitaria del español hablado en Alicante", en Interlingüistica, 14, 416-419.

Alvarado Ortega, M. ${ }^{a}$ B. (2004): "Lo que se comunica en las fórmulas expresivas", en Interlingüística, $15,1,125-132$.

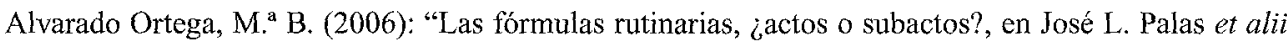
(eds.), Discurso y sociedad, contribuciones al estudio de la lengua en el contexto social, Colección de Estudios Lingüisticos, 23, 153-162.

Alvarado Ortega, M. ${ }^{a}$ B. (2008): Las fórmulas mutinarias en el español actual, Alicante, Universitat, Tesis doctoral (inédita).

Bentivoglio, P. (1991): "Análisis de la variación lingüística en el español de América: una propuesta metodológica", en El español de América: Actas del III Congreso Internacional del Español en América, Valladolid, 9 de julio de 1989, vol. 2, 947-954.

Briz Gómez, A. (1998): El español coloquial en la conversación. Esbozo de pragmagramática, Barcelona, Ariel.

Briz Gómez, A. (dir.) (2000-2008): Presentación del Diccionario de partículas discursivas del español: http://dpde.es (01-05-08).

Briz Gómez, A. y Grupo Val.Es.Co. (2000): ¿Cómo se comenta un texto coloquial? Barcelona, ArielPracticum.

Briz Gómez, A. y Grupo Val.Es.Co. (2002a): Corpus de conversaciones coloquiales. en Oralia, Madrid, Arco/Libros.

Briz Gómez, A. y Grupo Val.Es.Co. (2003): "Las unidades de la conversación: el acto", en Girón Alconchel, J. L. y otros (eds.): Estudios ofrecidos al profesor J. J. de Bustos Tovar, vol. II, Madrid, Editorial Complutense, 953-968.

Briz Gómez, A., A. Hidalgo, X. Padilla, S. Pons, L. Ruiz Gurillo, J. Sanmartín, E. Benavent, M. Albelda, M. J. Fernández y M. Pérez (2003): "Un sistema de unidades para el estudio del lenguaje coloquial", Oralia, 6, 7-61.

Briz Gómez, A., Pons, S y J. Portolés (eds.) (2000-2008): Diccionario de particulas discursivas del español (DPDE): http://dpde.es (01-05-08).

Christl, J. (1996): "Muletillas en el español hablado", en Kotschi, T., W. Oesterreicher y K. Zimmermann (eds.) (1996): El español hablado y la cultura oral en España e Hispanoamérica. Frankfurt am Hain, Vervuert Verlag, Bibliotheca Iberoamericana, 117-143.

Corpas, G. (1996): Manual de fraseología española, Madrid, Gredos.

Cortés Rodríguez, L. (1991): Sobre conectores, expletivos y muletillas en el español hablado. Málaga, Ed. Librería Ágora.

Cortés Rodríguez, L. (1998): "Marcadores del discurso y análisis cuantitativo", en Martín Zorraquino, M. A. y E. Montolío Durán (coords.), 143-160.

Cortés Rodríguez, L. (2002): "Las unidades del discurso oral", Boletín de lingüistica, 17, Universidad Central de Venezuela, 7-29. 
Cortés, L. y Camacho, Ma . M (2005): Unidades de segmentación y marcadores del discurso. Madrid, Arco/Libros.

DRAE, 2001, s.v. tal: www.rae.es.

Fraser, B. (1999): "What are discourse markers?", Journal of Pragmatics, 31, 931-952.

Gallardo Paúls, B. (1993): Lingüística perceptiva y conversación: secuencias, Anejo 4 de LynX. Departamento de Teoría de los Lenguajes, Universidad de Valencia.

Gallardo Paúls, B. (1996): Análisis Conversacional y Pragmática del receptor. Valencia, Ediciones Episteme S.L., Colección Sinapsis.

Gille, J. y Häggkvist, C. (2006): "Los niveles del diálogo y los apéndices conversacionales", en Discurso, interacción e identidad. Homenaje a Lars Fant. Stöckholms Universitet, Institutionem för Spanska, Portugisiska och Latinamenkastudier, 65-80.

Gómez Molina, J. R. (coord.) (2001): El español hablado en Valencia. Materiales para su estudio (PRESEEA). I. Nivel sociocultural alto, Anejo XLVI de Quaderns de Filologia, Departamento de Filología Española, Grupo Val.Es.Co, Universitat de València.

Gómez Molina, J. R. (coord.) (2005): El español hablado en Valencia. Materiales para su estudio (PRESEEA). II. Nivel sociocultural medio, Anejo LVIII de Quaderns de Filologia, Departamento de Filología Española, Universitat de València.

Gómez Molina, J. R. (coord.) (2007): El español hablado en Valencia. Materiales para su estudio (PRESEEA-Valencia). III. Nivel sociocultural bajo, Anejo LXI de Quaderns de Filologia, Departamento de Filología Española, Universitat de València.

Hansen, M. M. (e. p.): "Lexical-semantics/pragmatics: Synchronic issues". En Particles at the lexicalsemantics / pragmatics interface: synchronic issues. Oxford, Elsevier, cap. 2.

Hidalgo, A. (2006): "Estructura e interpretación en la conversación coloquial: el papel del componente prosódico", Revista de Filologia, 24, 129m151.

Hidalgo, A. y X. Padilla (2006): "Bases para el análisis de las unidades menores del discurso oral: los subactos", Oralia, 9, 109-139.

Lema, diccionario de la lengua española [dir. Paz Battaner Arias] (2001), Barcelona, Vox, 17091710.

Marcos Marín F. J.-Satorre, J.-Viejo, M. ${ }^{a}$ L. (1998): Gramática española, Madrid, Síntesis, 179-188.

Martín Zorraquino, M. ${ }^{a}$ A. y E. Montolío Durán (coords.) (1998): Los marcadores del discurso. Teoria $y$ análisis. Madrid, Arco/Libros.

Martín Zorraquino, M. a A. y J. Portolés Lázaro (1999): "Los marcadores del discurso". En Bosque, I. y Demonte, V. (eds.): Gramática descriptiva de la lengua española (I). Madrid, Espasa Calpe, $2^{\mathrm{a}}$ reimpr., 4051-4203.

Moeschler, J. (1985): Argumentation et conversation. Eléments pour une analyse pragmatique du discours. Université de Genève, Hatier-Credif.

Moliner, M. (1998): Diccionario de uso del español, Madrid, Gredos, $2^{\text {a }}$ ed., 2 vols.

Moliner, M. (2004): Diccionario de uso del español. Madrid, Gredos, $2^{\mathrm{a}}$ ed. (versión electrónica).

Montañez Mesas, M. P. (2007a): Marcadores discursivos y posición final. A propósito de ¿eh? y ¿no?. Universitat de València, Trabajo de Investigación (inédito).

Montañez Mesas, M. P. (2007b): "marcadores del discurso y posición final: la forma ¿eh? en la conversación coloquial española", ELUA, 21, Alicante, 261-280.

Montañez Mesas, M. P. (e. p.): "Marcadores del discurso y posición final: a propósito de ¿eh?", $A J L$, Girona, aceptado para publicación en Interlingüística, 2008.

Montañez Mesas, M. P. (e. p.): "El apéndice ¿no? en la conversación coloquial española", Boletín de Filologia de la Universidad de Chile.

Moreno Fernández, F. (1994): "Status quaestionis: sociolingüística, estadística e informática", en Lingüistica (ALFAL), 6, 95-154.

Pons, S. (1998a): Conexión y conectores. Estudio de su relación en el registro informal de la lengua. Anejo XXVII de Cuadernos de Filología, Universitat de València. 
Portolés, J. (1998): Marcadores del discurso, Barcelona, Ariel, 1998.

Real Academia Española (2005): Diccionario de la lengua española. $23^{\mathrm{a}}$ ed. versión electrónica: www. rac.es $(01-05-08)$

Rona, J. P. (1974): "La concepción estructural de la sociolingüística", en Antología de estudios de etnolingüística y sociolingüistica, México, 203-216.

Roulet, E., A. Auchlin, J. Moeschler, C. Rubattel, y M. Schelling, (1991): L'articulation du discours en français contemporain. Berne, Peter Lang, $3^{\mathrm{a}}$ ed. ( $\mathrm{l}^{\mathrm{a}}$ ed., 1985)

Ruiz Gurillo, L. (1996): "Sobre la fraseología coloquial: corpus e investigación", en Actas del I Congreso Internacional de AESLA (Granada, septiembre de 1992), 493-498.

Ruiz Gurillo, L. (1998): La fraseología del español coloquial, Barcelona, Ariel Practicum.

Sacks, H., E. Schegloff y G. Jefferson, (1974): "A simplest systematics for the organization of turntaking for conversation", Language, 50, 4, 696-735.

Sankoff, D. "Sociolingüística y variación sintáctica", en: Newmeyer, F. J. (ed.) (1992), Panorama de la lingüistica moderna de la Universidad de Cambridge. Vol. IV (El lenguaje: el contexto sociocultural), Madrid, Visor, 173-192.

Santos Río, L. (2003): Diccionario de partículas, Salamanca, Luso-Española de Ediciones, 615-616. Schiffrin, D. (1987): Discourse markers. Cambridge University Press.

Seco, M., Andrés, O. y Ramos, G. (1999): Diccionario del español actual, Madrid, Aguilar, $2^{\mathrm{a}}$ reimp., 2 vols., 4237-4238.

Silva-Corvalán, C. (2001): Sociolingüística y pragmática del español, Georgetown University Press, Washington D. C.

Silva-Corvalán, C. (1994): "Direcciones en los estudios sociolingüísticos de la lengua española", en Actas del Congreso de Lengua Española (Sevilla, 7-10 de octubre de 1992), Madrid, Pabellón de España, 399-415.

Silva-Corvalán, C., "Variación sintáctica en el discurso oral: problemas metodológicos", en Moreno Fernández, F., (coord.) (1997), Trabajos de sociolingüística hispánica, 115-136. 